\title{
Preparation and Characterization of (PVA+ZnO) Polymer Films Doped With $\mathrm{Cu}^{2+}$ Ions
}

\author{
Ch. Rani, S. Hima Bindu, M. Hemalatha, Ch. Linga Raju* \\ Department of Physics, Acharya Nagarjuna University, Nagarjuna Nagar-522510, A.P, India
}

\begin{abstract}
PVA+ZnO): (x mol\%) $\mathrm{Cu}^{2+}$ ions doped polymer films were prepared by solution casting technique. The obtained films are analyzed using different characterization techniques like SEM, FTIR, optical and EPR. The SEM micrographs shows the improvement in the crystallinity of the $\mathrm{Cu}^{2+}$ doped PVAZn polymer films compared with the pure PVAZn film. The Fourier transform infrared spectroscopy (FTIR) spectrum shows a characteristic peaks of $\mathrm{C}-\mathrm{H}, \mathrm{C}=\mathrm{C}, \mathrm{CH}_{2}$ and $\mathrm{C}$-O bonds. The optical absorption spectrum exhibits broad bands at $412 \mathrm{~nm}$ and $692 \mathrm{~nm}$, which were corresponds to the ${ }^{2} B_{l g} \rightarrow{ }^{2} E_{g}$ and ${ }^{2} B_{l g} \rightarrow{ }^{2} B_{2 g}$ transition. The EPR spectra of all the polymer samples exhibits resonance signals characteristic of $\mathrm{Cu}^{2+}$ ions. The spin-Hamiltonian

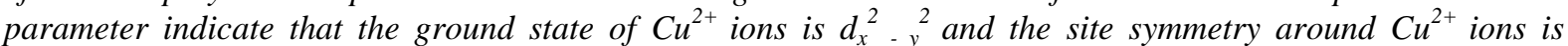
tetragonally distorted octahedral site. The number of spins participating in resonance $(N)$ and paramagnetic susceptibility $(\chi)$ were calculated from the EPR data for various concentrations of $\mathrm{Cu}^{2+}$ ions.
\end{abstract}

\section{Introduction}

Polymers have potential applications as permanent and transient data storage materials or as basic materials to the fabrication of active and passive light guides. In the holographic recording, "ion" doped organic polymers are highly efficient compared with other polymer films [1]. The main advantage of the polymer films are simplicity of their preparation. The present system consists of simple combinations of poly (vinyl alcohol) and zinc acetate as host materials. PVA is important due to its enhanced properties in industrial, commercial, medical and food applications [2]. PVA is the most widely produced water-soluble synthetic polymer having a wide range of dopant dependent properties. It has a good resistance and excellent physical properties [3]. Surface capping by PVA is useful in achieving a higher and relatively steady UV sensitivity in $\mathrm{ZnO}$ materials. Zinc is one of the best promising materials for electrical devices, including transparent conductive films, light emitting diodes and photo-catalyst [4]. In particular, introducing $\mathrm{ZnO}$ into polymeric matrices can modify the optical, electrical and mechanical properties of polymer films [5]. The doping of copper ions into the host material will influence the packing efficiency, which change the thermal properties of the polymer material [1].

\section{Experimental}

Analytical grade of poly (vinyl alcohol), Zinc Acetate and copper sulphate $\left(\mathrm{CuSO}_{4} .5 \mathrm{H}_{2} \mathrm{O}\right)$ purchased from Himedia, Mumbai, India and double distilled water is used as solvent throughout the experiment.The $5 \mathrm{~mol} \%$ of each PVA and zinc acetate were dissolved in double distilled water separately and stirred with magnetic stirrer until the chemicals completely dissolved and forms a clear viscous solution. Then the desired volume of both solutions were mixed and stirred for $30 \mathrm{~min}$. The desired concentration of $\mathrm{CuSO}_{4} .5 \mathrm{H}_{2} \mathrm{O}(0.2$, $0.4,0.6 \& 0.8 \mathrm{~mol} \%)$ solutions were added drop wise to the prepared $5 \mathrm{~mol} \%$ of $(\mathrm{PVA}+\mathrm{ZnO})$ solution and stirred thoroughly with magnetic stirrer for another $30 \mathrm{~min}$. Then the solution was casted on petri dishes and the films were collected after 7 days. Here after the combination of $(\mathrm{PVA}+\mathrm{ZnO})$ polymer films were referred as PVAZn polymer films. The surface and cross sectional morphology of the pure PVAZn and copper doped PVAZn polymer films were recorded using Hitachi make model, S-2830N, Japan made Scanning Electron Microscope (SEM).

The infrared absorption spectra of the polymer films were measured at room temperature in the wave number rage 2000-600 $\mathrm{cm}^{-1}$ by a Jasco, FT-IR130 Japan make Fourier Transform computerized infrared spectrophotometer. The optical absorption spectra of the folded polymer samples (thickness $1 \mathrm{~mm} \pm 0.1 \mathrm{~mm}$ ) recorded at room temperature using a dual-beam spectrophotometer JASCO V-670, Japan in the wavelength range 400-800 nm. X-Band EPR spectra were recorded on a Bruker EMX X-band EPR spectrometer working at $9.15 \mathrm{GHz}$ using a rectangular cavity operating at a $100 \mathrm{kHz}$ modulation frequency at room temperature.

\subsection{Scanning Electron Microscope (SEM)}

\section{Results and discussions}

The surface morphology of the PVA+ZnO films are studied with SEM images. The SEM images of pure and $\mathrm{Cu}^{2+}$ doped PVAZn polymer films are shown in Fig.1 (a) and (b). The prepared films have homogeneous distribution of $\mathrm{Zn}$ particles. When copper ions introduced in to the PVAZn matrix and compared 
with the pure polymer matrix. The $\mathrm{PVAZn}: \mathrm{Cu}^{2+}$ film shows spherical grain distribution with a uniform density. The clear change in surface morphology was observed with the $\mathrm{Cu}^{2+}$ ion doped in PVAZn polymer film.

\subsection{Fourier transform infrared studies}

The FTIR spectra of pure and $\mathrm{Cu}^{2+}$ doped PVAZn polymer films were shown in Fig.2. The FTIR spectra consist of several groups of bands for the undoped and copper doped polymer films. The main bands observed in the range of $610-691 \mathrm{~cm}^{-1}$ has been assigned to $\mathrm{Zn}-\mathrm{O}$ stretching of the polymer complex [6]. The main band at $837 \mathrm{~cm}^{-1}$ has been assigned to $\mathrm{C}-\mathrm{C}$ stretching mode of the host polymer. The bands observed at $1000-1100 \mathrm{~cm}^{-1}$ has been assigned to C-O-C stretching mode formed by the cross linking reaction of PVA with $\mathrm{ZnO}$ and the bands around $1450-1558 \mathrm{~cm}^{-1}$ has been assigned to bending vibrations of $\mathrm{CH}_{2}$ of PVA group [7]. The band at 1642 and $1702 \mathrm{~cm}^{-1}$ has been assigned to stretching mode of $\mathrm{C}-\mathrm{O}$. The main change for the undoped and copper doped polymer is shifting of the absorption bands. The $\mathrm{Zn}-\mathrm{O}$ bands at 616 and $667 \mathrm{~cm}^{-1}$ for pure PVAZn polymer shifts towards the 641 and $691 \mathrm{~cm}^{-1}$ in the $\mathrm{Cu}^{2+}$ PVAZn polymer film. This indicates the cross linking of $\mathrm{Cu}-\mathrm{O}$ with $\mathrm{Zn}-\mathrm{O}$ in the host polymer [8]. The band at $837 \mathrm{~cm}^{-1}$ shifts towards to the lower region 796 $\mathrm{cm}^{-1}$, which has been assigned to $\mathrm{C}-\mathrm{C}$ mode indicating the amorphous nature of the sample. The band at 1702 $\mathrm{cm}^{-1}$ became broaden in the doping of $\mathrm{Cu}^{2+}$ ions in PVAZn polymer due to the alteration of PVA chains with $\mathrm{Zn}-\mathrm{O}$ and $\mathrm{Cu}-\mathrm{O}$. Therefore introducing the $\mathrm{Zn}-\mathrm{O}$ and $\mathrm{Cu}-\mathrm{O}$ in the PVA structure modifies the semi crystalline structure of PVA confirming the cross linking of metal ions with the main chain of the PVA. The observed band positions and their corresponding band assignments presented in Table 1.

\subsection{Optical absorption studies}

The room temperature optical absorption spectra were recorded for $\mathrm{Cu}^{2+}$ ions doped PVAZn polymer film in the wavelength range $400-800 \mathrm{~nm}$. The absorption spectra exhibit two absorption bands at 412 and 692 $\mathrm{nm}$ respectively. There is no specific change in the band positions except variation in intensity of the bands with the concentration. Hence as a remarkable spectrum, the absorption spectrum of $(0.2 \mathrm{~mol} \%) \mathrm{Cu}^{2+}$ doped PVAZn polymer film is given as Fig.3. The broad band at $692 \mathrm{~nm}$ has been assigned to ${ }^{2} \mathrm{~B}_{1 \mathrm{~g}} \rightarrow{ }^{2} \mathrm{~B}_{2 \mathrm{~g}}$ transition of $\mathrm{Cu}^{2+}$ ion in a distorted octahedral site and the band at $412 \mathrm{~nm}$ has been assigned to ${ }^{2} \mathrm{~B}_{1 \mathrm{~g}} \rightarrow{ }^{2} \mathrm{E}_{\mathrm{g}}$ transition [1].

The investigations of optical transitions and electronic band structure can be analyzed using the fundamental absorption edge in the UV region of the optical absorption spectrum. The main feature of the absorption edge is an exponential increase of the absorption coefficient $\alpha(v)$ with photon energy $h v$ [9]. The absorption coefficient $\alpha(v)$ can be calculated using the formula,

$$
\alpha(v)=(A / d) 2.303
$$

where $A$ is the absorbance at frequency ' $v$ ' and ' $d$ ' is the thickness of the sample. The optical band gap for direct and indirect transitions can be determined by using the relation,

$$
\boldsymbol{E}_{\text {opt }}=\boldsymbol{h v}-(\boldsymbol{a} \mathrm{hv} / \mathrm{B})^{1 / 2}
$$

where $B$ is a constant. The direct and indirect band gaps were calculated from the plots of $(\alpha h v)^{2}$ and $(\alpha h v)^{1 / 2}$ as a function of photon energy ( $h v$ ) and are shown in Fig.4(a) and (b). The corresponding values are taken by extrapolating the linear portion of absorption coefficient meet at $\mathrm{x}=0$.

Urbach plots are the natural logarithm of absorption coefficient $\ln (\alpha)$ is plotted against photon energy (hv). In the present study such an Urbach plots were plotted and are shown in Fig.5. The direct, indirect optical band gaps and Urbach energies were calculated with respect to the copper concentration in the PVAZn polymer films and are presented in Table 2. From the Table, it is observed that the direct and indirect band gap energies decrease with the increase of copper concentration. This may be due to the loose packing of the host complex with the copper.

\subsection{Electron paramagnetic resonance (EPR)}

The EPR spectrum of the undoped polymer film confirming that the starting materials used in the present work were free from transition metal impurities or any other paramagnetic contamination. When various mol\% of $\mathrm{CuSO}_{4}$ were added to PVAZn films, the EPR spectra of all the investigated samples exhibits a well resolved resonance signals as shown in Fig.6. The EPR spectrum exhibits four parallel and one perpendicular line for the samples under study. For $\mathrm{Cu}^{2+}$ ions, a regular octahedral site may not exist because the cubic symmetry is disturbed by electronic-hole in the degenerate $\mathrm{d}_{\mathrm{x}-\mathrm{y}}{ }^{2}$ orbital and this produces the tetragonal distortion. The EPR spectra of $\mathrm{Cu}^{2+}$ ions in the present polymer film can be well interpreted in terms of the spinHamiltonian for $\mathrm{d}^{9}$ ions in an axial symmetry [10],

$$
\mathscr{H}=\beta\left[g_{11} H_{z} S_{z}+g_{\perp}\left(H_{x} S_{x}+H_{y} S_{y}\right)\right]+A_{11} I_{z} S_{z}+A_{\perp}\left(I_{x} S_{x}+I_{y} S_{y}\right)
$$

where the terms have their usual meanings given in our previous papers [11]. 
In EPR spectrum, one can get four parallel and four perpendicular signals for copper ions. However, in the present study, we observed only four parallel and one perpendicular signals due to ${ }^{63} \mathrm{Cu}$ and ${ }^{65} \mathrm{Cu}$ isotopes. The spectral parameters for all the samples are well resolved with four parallel components $\left(\mathrm{g}_{\|} \approx 2.38\right)$ and a perpendicular component around $\left(\mathrm{g}_{\perp} \approx 2.05\right)$. The observed $\mathrm{g}$ and $\mathrm{A}$ values are presented in Table 3 . From the table, it can be observed that, the $\mathrm{g}$ values follows the trend $\mathrm{g}_{\|}>\mathrm{g}_{\perp}>2.0023$. We consider that the ground state for the paramagnetic electrons is $\mathrm{d}_{x-y}^{2}{ }^{2}$ orbital and the $\mathrm{Cu}^{2+}$ ions being located in the distorted octahedral sites $\left(\mathrm{D}_{4 \mathrm{~h}}\right)[12-15]$.

\section{4 (a) Calculation of spin concentration (N)}

The number of spins participating in resonance can be calculated by comparing the present system with standard known concentration of $\mathrm{CuSO}_{4} .5 \mathrm{H}_{2} \mathrm{O}$. The well - known expression given by Weil et al., [16] was used to calculate the spin concentration in the present work and is given by,

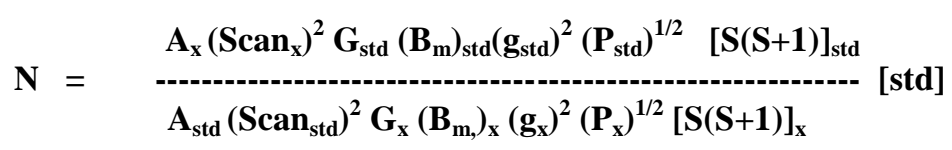

where the terms have their usual meanings [11].

The spin concentration $(\mathrm{N})$ participating in resonance for the present system was calculated for different concentrations of copper ions $(0.2$ to $0.8 \mathrm{~mol} \%)$ and a plot was drawn between copper concentrations against spin concentration for this polymer system and is shown in Fig.7. From the graph, it can be observed that the spin concentration participating in resonance $(\mathrm{N})$ has a non-monotonic (i.e., increases then decrease) behavior with the increase in concentration. This may be due to the presence of other copper states existing in the polymer complex [17].

\section{4 (b) Paramagnetic susceptibility}

The paramagnetic susceptibility of the polymer films at room temperature was calculated from the EPR data using the formula [18],

$$
\chi=\frac{\mathrm{Ng}^{2} \boldsymbol{\beta}^{2} \mathbf{J}(\mathbf{J}+\mathbf{1})}{-3 \mathbf{K}_{\mathbf{B}}(\mathbf{T})}
$$

where the terms have their usual meanings [11]. The paramagnetic susceptibilities were calculated for PVAZn: $\mathrm{Cu}^{2+}(0.2-0.8 \mathrm{~mol} \%)$ polymer films and a plot was drawn for the reciprocal of susceptibility $(1 / \chi)$ as a function of concentrations is shown in Fig.8. From the graph, the susceptibility of the samples decreases with the concentrations of copper in the host matrix.

\section{Conclusions}

$>\mathrm{PVAZn}: \mathrm{Cu}^{2+}$ polymer films were prepared by solution casting technique at room temperature.

> The clear and uniform surface structure was observed from the Scanning electron microscopy (SEM).

$>$ From the EPR and optical absorption spectral studies, the $\mathrm{Cu}^{2+}$ ions occupied in tetragonally distorted octahedral sites in the host matrix.

$>$ The decrease in paramagnetic susceptibility indicates the increase in amorphous nature of the sample.

The FT-IR spectrum exhibits the $\mathrm{Zn}-\mathrm{O}, \mathrm{CH}_{2}, \mathrm{C}-\mathrm{H}, \mathrm{C}=\mathrm{O}, \mathrm{C}=\mathrm{C}$ groups of stretching and bending vibrations.

\section{References}

[1] Ch. Linga Raju, J.L. Rao, B.C.V. Reddy and K.Veera Brahmam, Bull Mater. Sci., 30 (3) ( 2007) 215-218.

[2] Hongtao Fan, Yuqian Bian, Dianpeng Sui, Guifeng Tong and Ting Sun, Aalytical Sciences, 25 (2009) 1345-1349.

[3] Seon Jeong Kim, Seonng Gil Yoon, Young Moo Lee and Sun I Kim, Sensors and Actuators, B-88 (2003) $286-291$.

[4] I. Latif, Entisar E, AL-Abodi, Dhe faf H. Badri and Jawad AI Khafagi, American Journal of Polymer Science, 2(6) (2012)135-140.

[5] Tapas Kumar Kundu,Nantu Karak, Puspendu Barik, Satyajit Saha International Journal of Soft computing and Engineering (IJSCE). 1 (2011) 2231-2307.

[6] S. Hima Bindu, D. Siva Raju, V. Vinay Krishna, T. Rajavardhana Rao, K. Veerabrahmam, Ch. Linga Raju. Optical Materials, 62 (2016) 655-665.

[7] Elizabeth Fonseca dos Reis, Fabia S. Campos, Andrey Pereira Lage, Romulo Cerqueira Leite, Luiz Guilherme Heneine, Wander Luiz Vasconcelos, Zelia Ines Portela Lobato, Herman Sander Mansur, Material Research, 9(2) (2006) 185-191.

[8] S. Gandhi. R. Hari Hara Subramani, T. Ramakrishanan, A. Sivabalan, V. Dhana Lakshmi, J.Mater. Sci., 45 (2010) $1688-1694$.

[9] E.A.Davis and M.F.Mott, Philos. Mag., 22 (1970) 903.

[10] B. Bleaney, A. Abragam, Electron paramagnetic Resonance of Transition ions, Oxford University Press, London, (1970) 186.

[11] T. Rajavardhana Rao, I. Omkaram, B. Sumalatha, K. Veera Brahmam, Ch. Linga Raju, Ionics, 18 (2012) 695.

[12] H.A. Jahn, E.Teller, Pproc. Royal Soc., London, 161 (1937) 220. 
[13] A.M. Klonkowski, C.W. Schlaepfer, Non-Cryst. Solids, 129 (1991) 101.

[14] S. Bale, S. Rahman, Non-Cryst. Solids., 355 (2009) 2127.

[15] G. Upender, M. Prasad, V. Chandra Mouli, Non-Cryst. Solids, 357 (2011) 903.

[16] J.A. Weil, J.R. Boltan, J.E. Wertz, Electron paramagnetic resonance - Elementary Theory and practical applications, Wiley, New York, (1994) 498.

[17] B. Sumalatha, I. Omkaram, T. Rajavardhana Rao, Ch. Linga Raju, Non-Cryst.Solids, 375 (2011) 3143-3152.

[18] N.W. Aschcroft, N.N. Mermin, Solid State Physics, Harcourt, Fort worth, TX, (2001) 656.

Table 1. FTIR band positions and their corresponding band assignments of PVAZn and $\mathrm{Cu}^{2+}$ ions doped PVAZn polymer films.

\begin{tabular}{|c|c|c|c|c|c|}
\hline & \multicolumn{5}{|c|}{ PVAZn:Cu $\mathbf{C u}^{\mathbf{2 +}}(\mathbf{m o l})$} \\
\cline { 1 - 4 } PURE PVA Zn & $\mathbf{0 . 2}$ & $\mathbf{0 . 4}$ & $\mathbf{0 . 6}$ & $\mathbf{0 . 8}$ & Band assignment \\
\hline 616 & 619 & 623 & 647 & 641 & $\mathrm{Zn}-\mathrm{O}$ \\
\hline 667 & 676 & 679 & 680 & 693 & $\mathrm{Zn}-\mathrm{O}$ \\
\hline 837 & 833 & 799 & 789 & 750 & $\mathrm{CH}_{2}$ \\
\hline 1080 & 1019 & 1022 & 1101 & 1147 & \multirow{2}{*}{$\mathrm{CO}$} \\
\hline 1137 & - & 1093 & 1146 & - & \multirow{2}{*}{$\mathrm{CH}_{2}$} \\
\hline 1459 & 1443 & 1444 & 1431 & 1463 & \multirow{2}{*}{$\mathrm{C}=\mathrm{C}$} \\
\hline 1521 & 1532 & 1517 & 1517 & 1516 & \\
\hline 1541 & - & 1558 & 1561 & 1558 & \multirow{2}{*}{} \\
\hline 1642 & 1619 & 1632 & 1640 & 1621 & \\
\hline 1702 & 1700 & 1686 & 1692 & 1682 & \\
\hline
\end{tabular}

Table 2. The direct, indirect band gaps and Urbach energies of $\mathrm{Cu}^{2+}$ ions doped PVAZn polymer films.

\begin{tabular}{|c|c|c|c|c|}
\hline S.No & $\mathbf{C u}^{2+}(\mathbf{m o l} \%)$ & Direct $(\mathbf{e V})$ & Indirect $(\mathbf{e V})$ & Urbuch energy $(\Delta \mathbf{E}, \mathbf{e V})$ \\
\hline 1 & 0.2 & 3.89 & 3.67 & 3.40 \\
\hline 2 & 0.4 & 3.82 & 3.40 & 2.78 \\
\hline 3 & 0.6 & 3.51 & 3.31 & 1.83 \\
\hline 4 & 0.8 & 3.29 & 3.13 & 1.34 \\
\hline
\end{tabular}

Table 3. The $\mathrm{g}$ values and the hyperfine splitting constant $(\mathrm{A})$ values of $\mathrm{Cu}^{2+}$ ions doped in PVAZn polymer films calculated using EPR spectra.

\begin{tabular}{|c|c|c|c|c|c|}
\hline S.No & $\mathbf{C u}^{\mathbf{2 +}}(\mathbf{m o l} \%)$ & $\mathbf{g}_{\|}$ & $\mathbf{g}_{\perp}$ & $\mathbf{A}_{\|} \mathbf{X 1 0 ^ { - 4 }}\left(\mathbf{c m}^{-\mathbf{1}}\right)$ & No. of $\mathbf{s p i n s}\left(\mathbf{1 0} \mathbf{2 5}^{\mathbf{2 5}} \mathbf{k g}\right)$ \\
\hline 1 & 0.2 & 2.45 & 2.08 & 138.4 & 1.214 \\
\hline 2 & 0.4 & 2.39 & 2.05 & 138.4 & 2.169 \\
\hline 3 & 0.6 & 2.39 & 2.07 & 138.4 & 1.9039 \\
\hline 4 & 0.8 & 2.38 & 2.07 & 130.9 & 1.4726 \\
\hline
\end{tabular}

Fig. 1(a) \& (b)

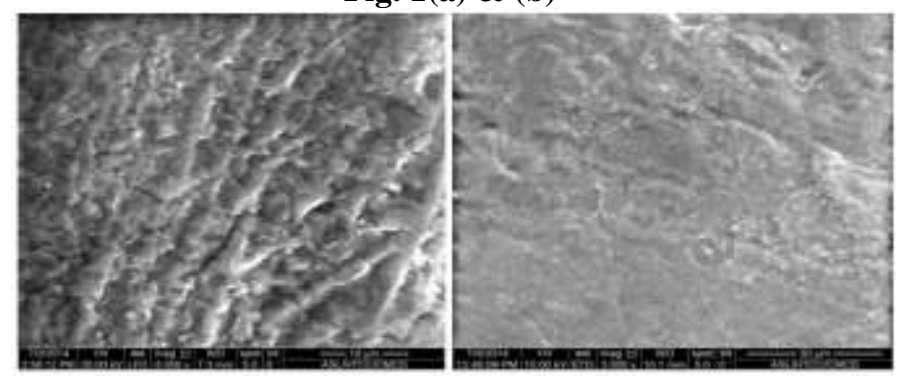

Fig.2

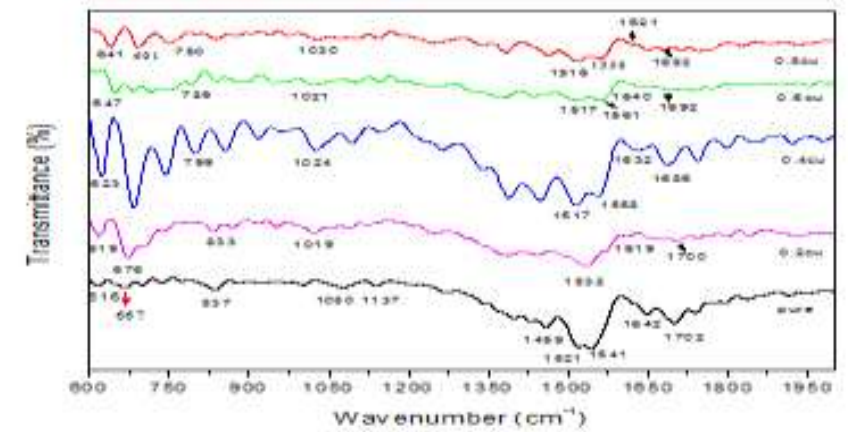


Fig.3

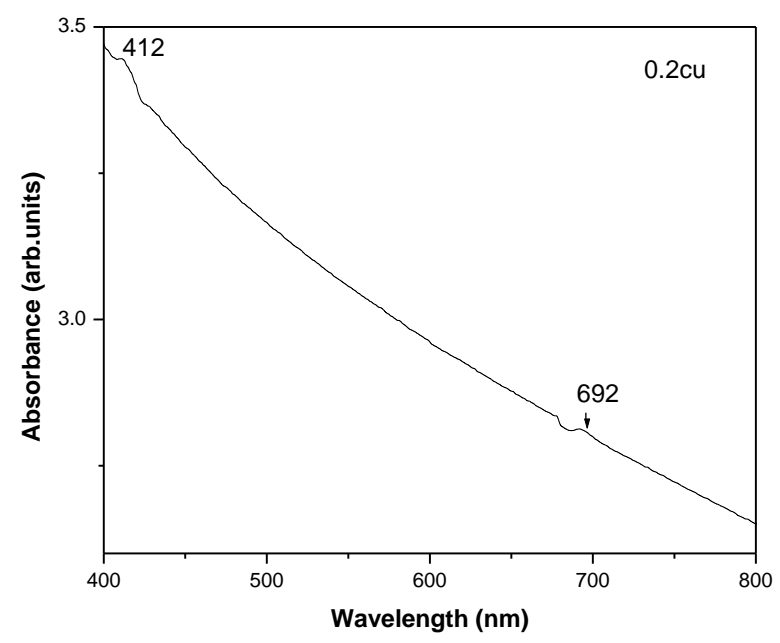

Fig.4 (a)

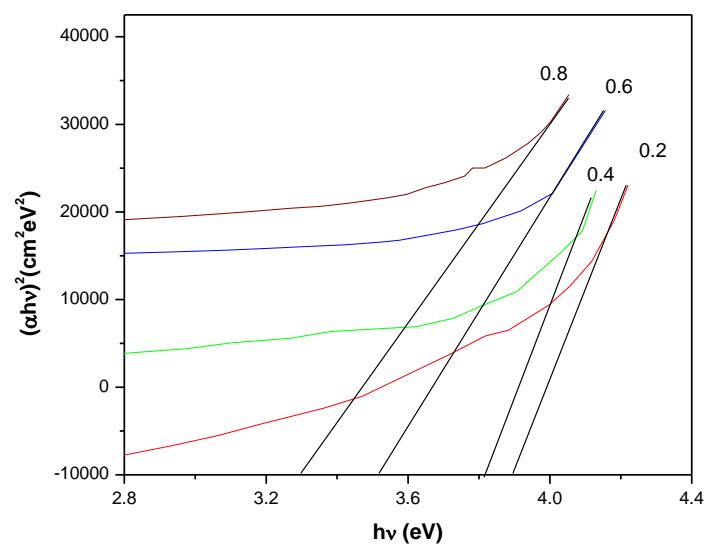

Fig.4 (b)

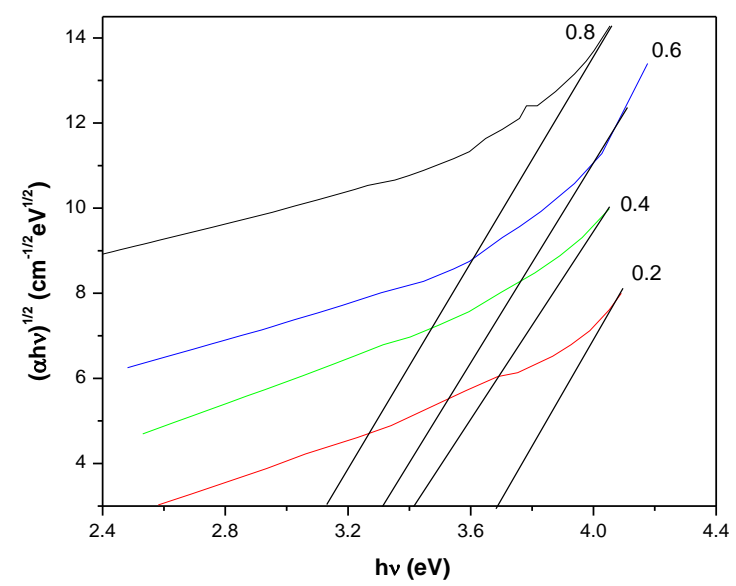




\section{Fig.5}

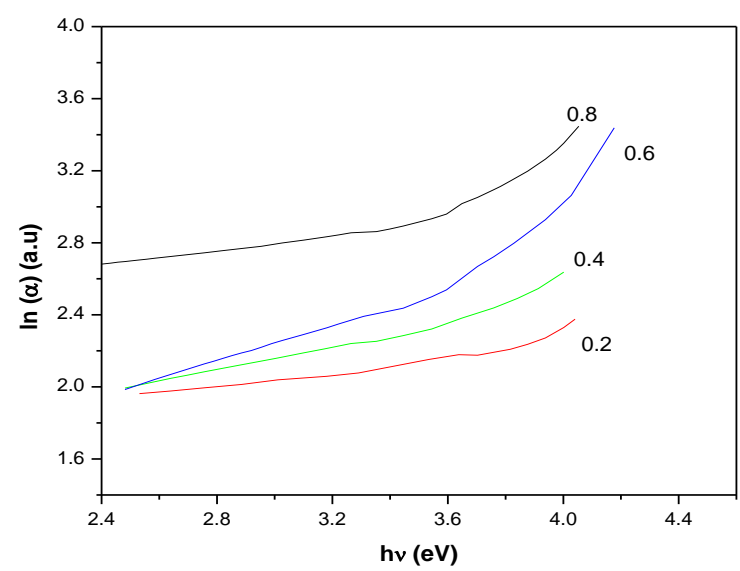

Fig.6

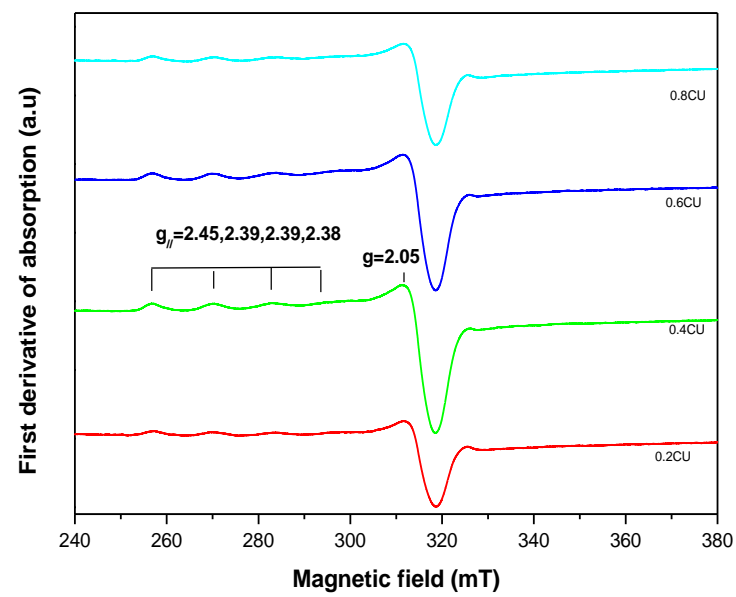

Fig.7

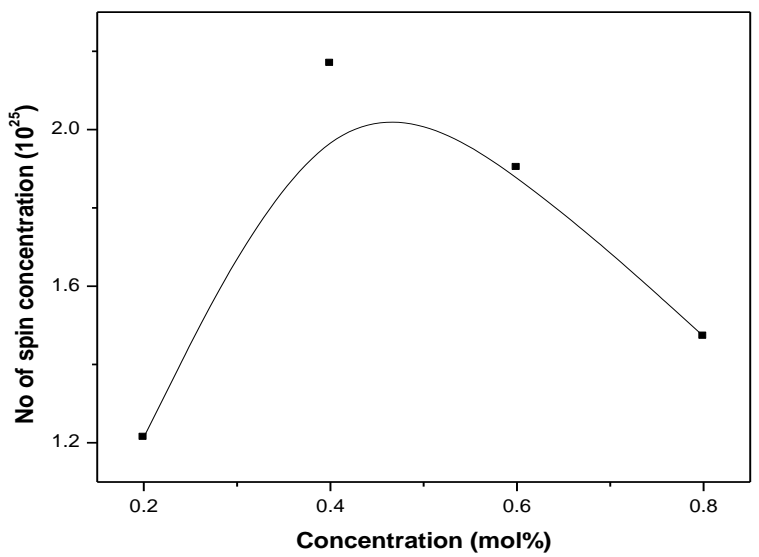




\section{Fig.8}

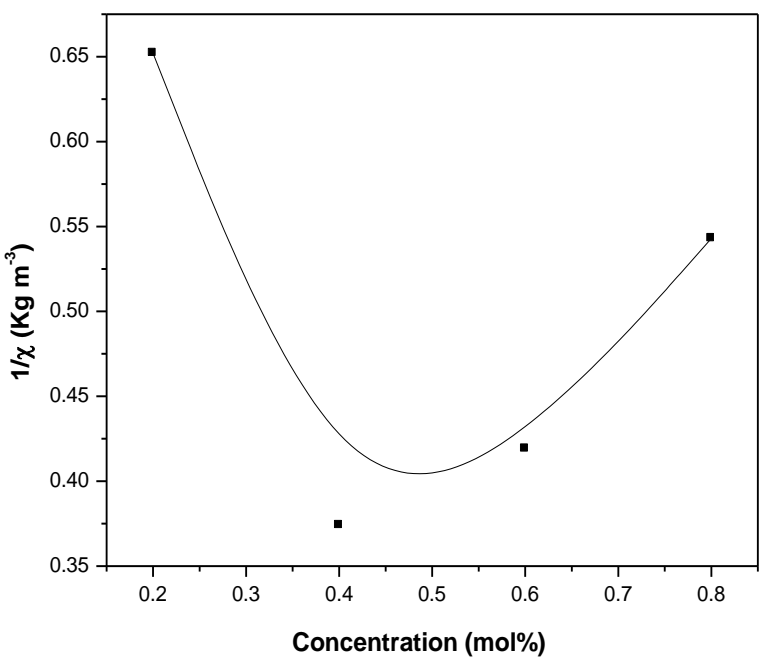

\section{Caption for figures:}

Fig.1: SEM images of (a) pure PVAZn and (b) $(0.4 \mathrm{~mol} \%) \mathrm{Cu}^{2+}: \mathrm{PVAZn}$ polymer film.

Fig.2: FTIR spectra of a pure PVAZn and $\mathrm{Cu}^{2+}: \mathrm{PVAZn}$ polymer films recorded at room temperature.

Fig.3: Optical absorption spectrum of $(0.2 \mathrm{~mol} \%) \mathrm{Cu}^{2+}: \mathrm{PVAZn}$ polymer film.

Fig.4: A plot of (a) $(\alpha h v)^{2}$ as a function of $h v$ and $(b)(\alpha h v)^{1 / 2}$ as a function of $h v$ for $\mathrm{Cu}^{2+}$ :PVAZn polymer films.

Fig.5: A plot of $\ln (\alpha)$ as a function of hv for PVAZn: $\mathrm{Cu}^{2+}$ polymer films.

Fig.6: EPR spectra of $\mathrm{Cu}^{2+}: \mathrm{PVAZn}$ films recorded at room temperature.

Fig.7: A plot of no.of spins (N) against concentration of copper in $\mathrm{Cu}^{2+}: \mathrm{PVAZn}$ polymer films.

Fig.8: A plot of reciprocal of susceptibility $(1 / \chi)$ as a function of copper concentration in $\mathrm{Cu}^{2+}: \mathrm{PVAZn}$ polymer films 